\title{
EMPOWERING EMPLOYEE'S PERFORMANCE BY VALUING THEIR EMOTIONAL INTELLIGENCE IN THE INTRA-INSTITUTIONAL COMMUNICATION ACT
}

\author{
Madlena NEN ${ }^{a}$, Corina Daniela BOGHEANU ${ }^{*}$, Horia Răzvan BOTIS ${ }^{c}$ \\ ${ }^{a, c}$ Military Technical Academy “Ferdinand I”, Bucharest, Romania \\ ${ }^{b}$ Bucharest University of Economic Studies, Romania
}

\begin{abstract}
This paper is intended to raise awareness about the importance of valuing the emotional intelligence in the intra-institutional communication act and to highlight the fact that the cooperation and the collaboration are the key elements for everyone's success. If we were asked what performance means to us, we would probably answer: success, competitiveness or high efficiency. The Romanian educational system encourages competitiveness to the detriment of collaboration and cooperation, but when we think of a situation in which we were energetic, powerful and proactive we realize that we were not alone. Thus, our personal performance is mainly due to the manner in which we know how to manage our interpersonal relationships with a focus on valuing our interlocutor's emotional intelligence. Managers are the main ones to be trained in this respect so that they can cascade a communication model down the organization in which the ability of employees to understand their own emotions and those of others has an important role to manage their emotions and channel them with a view to achieving their goals. The qualitative analysis of a few internal communication procedures from scholar organizations revealed the necessity of a communication model based on understanding the concept of emotional intelligence. The main results of the study are the change of the internal scholar communication procedures and a Google Drive accessible database at the scholar institution level that contains summary information/schemes about the intra-institutional communication, emotional intelligence and examples of good practice to avoid malfunctions or blockages in communication.
\end{abstract}

KEYWORDS: analysis of education, well-being, labor productivity, human development, social innovation

\section{DOI: 10.24818/IMC/2021/04.15}

\section{INTRODUCTION}

In the current social context dominated by the Covid19 pandemic with global effects, various aspects of the crisis are intensely felt socio-economic: financial, medical, political, cultural, but especially in terms of human relationships, which are known from other previous contexts to be rescuing and able to generate new energies. Regardless of the field of activity, all actions are based on interpersonal communication. The most optimal functioning of organizations and institutions occurs when employees are encouraged to show their interest in having an open mindset towards a particular type of communication and that is the assertive one and, of course, not only the employees, but also the managers, who, in our view, should be the first to be trained in this respect and should show a desire to promote such communication behaviour.

Figuratively speaking, the manager is the engine of a train running on a route of assertivity whose stops are: understood needs, cooperation, empathy, respect and politeness. Utopian, it might be said, especially in a pandemic context within which isolation, individualism, loneliness are the key

*Corresponding author. E-mail address: corina_bogheanu@yahoo.com 
aspects of the present-day situation. However, we will propose a resilience plan which exposes "non-invasive" methods to achieve the objective mentioned in the title: empowering employee performance due to their communication skills. How can this be achieved?

Firstly, we need to understand that this can be achieved by means of assertive communication and by raising awareness of the importance of removing barriers which may impede communication.

Consequently, the aim of this paper is to highlight the mechanisms that make assertive communication function, valuing the speaker's emotional intelligence and to outline a communication model that can be implemented in an organization, and through which employees and managers are encouraged to engage in such communication behavior based on their emotional intelligence.

Lange \& Jacubowski (1976) define assertion as standing up for personal rights and expressing thoughts, feelings and beliefs in direct, honest, and appropriate ways which do not violate another person`s rights. Taking into consideration Paul Watzlawick's axiom: One cannot not communicate (Watzlawick et al. 1967) and the idea that life, in general, involves us in many transactional communications, especially in our professional area, we need to think about how we can communicate better in order to be better, more creative, more efficient and more successful. How can I become better and better?

There are a lot of academic researches on communication science, as well as on emotional intelligence, but we want to link the two areas and build upon this knowledge in order to obtain a study to convey examples of good practice in organizations.

The aim of this paper is to emphasize the possibility of applying a communication model based on making the most of the emotional intelligence of those who engage in an intra-institutional communication (be it more or less formal) which, being followed within the organization, can add value to it, as regards training or strengthening the communication skills of participants, regardless of their hierarchical position in the organization. The indisputable benefits of it are: developing the skills to enhance the emotional intelligence of employees and managers and that means a contribution to making their communication skills more goal oriented and to learning through discovery and empathy; providing methods for developing emotional intelligence in adults which can lead to an awareness of the relationship between IQ and EQ and, therefore, to a higher degree of self-awareness, self-control and self-acceptance; creating the ability of efficient stress management; knowing techniques of interpersonal communication that can be practiced in order to encourage acceptance and appreciation of diversity.

We propose as a case study the analysis of the way in which the process of intra-institutional communication works in pre-university education system, following communication situations: manager-teachers, manager-pupils/students, teacher-pupils/students, students to students, managerstaff of attendants. Using the existent knowledge of the field of communication and emotional intelligence, we aim to emphasize practical methods through which such a communicational model can be implemented in each school institution based on stakeholders' emotional intelligence.

In this way, we will highlight the importance of valuing the emotional intelligence of participants in intra-institutional communication, given the fact that this is often ignored in practice, by presenting key aspects which are to be found in the theories of communication and in the field of emotional intelligence.

Also, we will present aspects of a communication model based on the value of emotional intelligence, which is easy to apply within a pre-university educational organization, including methods and practical opportunities to achieve its adoption in daily practice. Subsequently, we will look at the possibility of making it suitable for any type of organization providing educational services. 


\section{LITERATURE REVIEW}

\section{The interpersonal communication - Conceptualization}

Considering the two axioms by Paul Watzlawick, "One cannot not communicate", and "Every communication has a content and relationship aspect such that the latter classifies the former and is therefore a meta-communication" (Watzlawick et al., 1967), we understand that:

- Anyone inevitably communicates, because all type of behaviour implies communication, people who interact and are aware of each other are constantly communicating;

- The content of the communication/the message is understood according to the relationship between the communicators and therefore each person can respond differently.

Thus, the communication process is complex and influences all our living contexts, personal or professional. Consequently, we are interested in being good communicators in order to reach our goals, fulfill our responsibilities, establish the best human relationships so that we can be efficient both at work and at home. However, we are not always able to clearly express our points of view, ideas, concepts, and, as a result, communication is obstructed.

The effects of these barriers to communication are acutely felt both in personal life, in communication with family members or friends, and in professional life, and they can affect the employee performance, including managers themselves who may be subordinated to other managers.

In most cases, for example, in the Romanian school organisations, the employee feels that the intrainstitutional communication is usually a one-way process, from superiors to employees, and what employees communicate is less taken into consideration or only some employees are listened to. Our interest is to focus on operational procedures regulating the process of intra-institutional communication in pre-university schools in order to make a qualitative analysis and to show how communication works as linguists conceive the process.

\section{Jakobson's model}

Roman Jakobson (1896-1982) was a Russian-born American linguist, the pioneer of structural linguistics. In the article Linguistics and poetics, Jakobson (1960) distinguishes the parameters of any communication and underlines the existence of six language functions corresponding to these parameters:

(1) context-referential

(2) addresser (sender)-emotive

(3) addressee (receiver)-conative

(4) contact-phatic

(5) common code-metalingual

(6) message-poetic

The emotive function of the language is centered on the sender, but it can belong to the receiver when he responds and acts as locutor, which means that in any type of communication there is the emotional aspect. The speaker conveys not only the message but also his mood, feelings and values. Thus, we understand that the sender sends a message to the receiver, in a specific code, which can be the language or Morse Code etc., through a channel that can be the air or the telephone, the email, the fax, which are all happening within a context. The receiver, of course, may also become a sender. In any act of communication, the functions of the communication defined by Jakobson coexist, but their importance depends on the purpose of the communication, which may be emotional, persuasive, informative or predictive. The verbal structure of a message depends on the predominant function.

Consequently, in any act of language it is important to understand that as long as there is a sender, there will be the expressive/emotional function of the communication that conveys his emotional 
states as response to a given situation and that there will be a receptor on whom the conative function of the language takes effect, because this message is intended to persuade, inform or excite in order to obtain a certain verbal or behavioral response which depends not only on his intelligence quotient (IQ), but also on his emotional intelligence quotient (EQ), and cannot be adequate if any of the parameters of the communication are not functioning. For example, this may happen if the two people do not use the same code (language) or if the channel does not work etc. This is when communication blocks may appear.

\section{Communication blocks. Barriers to intra-institutional communication}

Communication blocks occur when certain barriers, whether physical or psychological, cannot be overcome. Torrington and Hall, identify five types of barriers (Pânișoară,2003):

$>$ Barriers to sending the message that occur only at the sender level;

$>$ Receiving barriers equally belonging to the receiver and the environment;

$>$ Barriers to understanding that lie both at the sender level (signal and jargon, communication skills, length of communication and channel) and at the receiver level (semantic issues, concentration, listening abilities, knowledge of the message, prejudices, receptiveness to new ideas

$>$ Barriers to acceptance work across all the indicators involved (sender, receiver and environment)

Action barriers are on both the sender and receiver

The causes of these barriers can be: difference in representation (age, education, culture, temperament, gender); religious, ethnic differences; lack of interest and individualism; lack of knowledge; difficulties in using a specific code, a foreign language, for example.

In order to reduce the situations in which barriers appear in communication, an important role is played in the organization by the manager whose aim is to increase employee performance and to that purpose he should overbid not only their IQ, but also their EQ, where EQ is the emotional intelligence quotient. Valuing the emotional intelligence of employees in order to develop their assertive communication skills can increase their productivity and their effectiveness as a result of positive social climate, wellness and increased self-esteem.

A communication model based on valuing the emotional intelligence of employees used in an organization can led to added value thanks to emotional intelligence-efficient and assertive communication-behavior triad.

So, further we want to analyze some public-school internal communication procedures to observe how the intra-institutional communication is conceived.

\section{METHODOLOGY}

We propose as a first case study an internal communication procedure (current and periodical communication) carried out at Stefan cel Mare Secondary Pedagogical High School in Bacău: Code document: PO_71', applied from 1.11.2017 (Tuţu, 2017).

In this document we can find a description of the intra-institutional communication process step by step. Firstly, the communication takes place in the teachers' meetings, in the meetings of the management board and school staff, in the departmental meetings, in working committees, in functional services.

Minutes shall be drawn up at the meetings in special Commission registers. A summary of these meetings shall be displayed and communicated. As a general rule, the principal communicates to teaching staff the latest information during the school stuff meetings and, in the event that important decisions are taken during the meetings of the management board, the Deputy Principal or Principals communicate the directions to be followed. Non-verbal communication is made through 
displaying information on staffroom notice boards in school, as well as by forwarding important messages for teachers to their e-mail addresses, by SMS, fax, landline and mobile.

The most part of the documents used in school are electronically stored. Non-electronic documents are scanned, if it's possible. All documents are supposed to be posted on the school portal. The exception is personal data.

This operational procedure is public and can be analyzed from the perspective of the effectiveness of the communicational process and the way in which human relationships are designed at an institutional level. Even if this document is dated 1.11.2017, we know from experience that nothing has changed till our present, because bureaucracy still exist and these procedures are only formal. In this organization the intra-institutional communication does not involve all the stakeholders in the same degree. More than that, there are some confusions regarding the different types of communication. For example, non-verbal communication is made through displaying information on staffroom notice boards in school, as well as by forwarding important messages for teachers to their e-mail addresses, by SMS, fax, landline and mobile shows that the authors confuse the channel of communication with the non-verbal communication, which means communicating through gestures or through facials expressions.

In the following image (figure 1) taken from the operational procedure on internal, external and institutional communication in the UPB's Polytechnic Primary School, we can see how the internal communication plan is conceived.

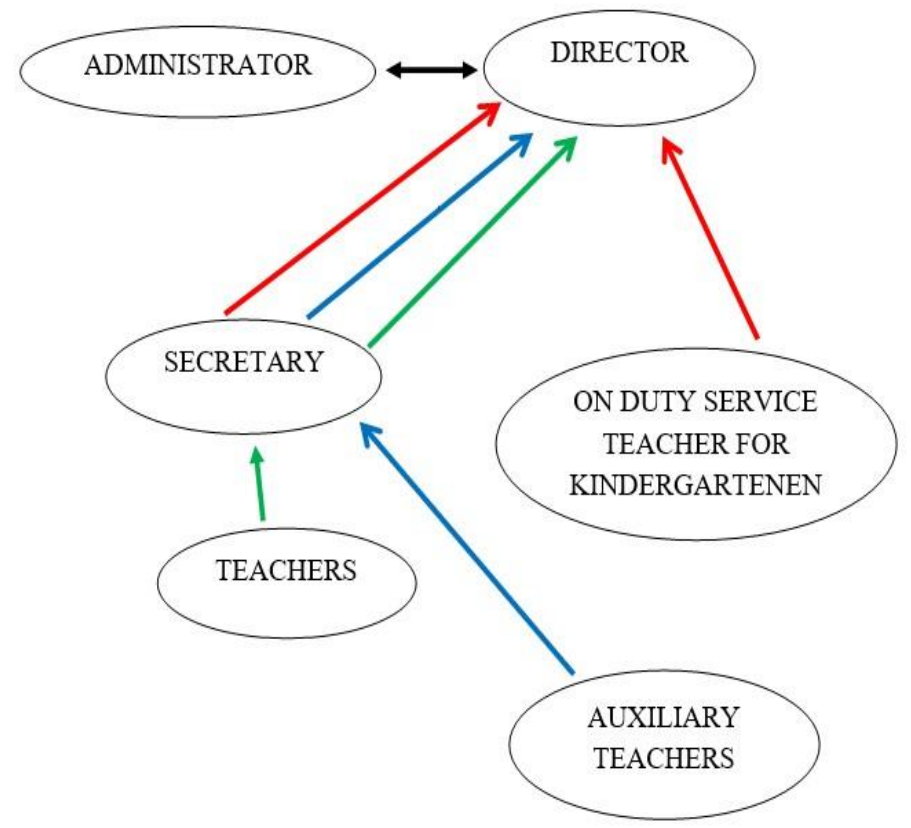

Figure 1. UPB's Polytechnic Primary School internal communication procedure Source: Authors, adapted by http://www.imst.pub.ro/Upload/Facultate/asigurarea_calitatii/PO21-SPP10_comunicare_interna.pdf

This Annex does not take into consideration two-way or multi-directional communication, despite the fact that all these actors should be involved in it: teachers, secretary, administrator are supposed to communicate and interact in the activities of the school organization.

Our interpretation of this image is that the secretary and teachers communicate, being of course subordinated to the principal, but it is only him who communicates with the administrator. And since the arrows are not bidirectional, it means that the principal does not communicate with his employees, but is informed by the secretary and the teacher on duty in the kindergarten. 
Upon further examination, we conclude that internal communication in school organizations is looked upon as the links of a chain: Principal-Deputy - departmental committees which have recently been replaced with working commissions, which have an informal contact memberteachers/school staff, that is one-way communication and often ineffective, especially because of the position of the employee/teacher whose version is not listened to by anyone, or by trade unions, and thus communication is not what is expected to be and that is a two-way process.

However, interpersonal communication is a two-way process which is established between two or more people within a context and requires a reference social framework upon which one must agree. Interpersonal communication is the main vehicle as regards the relational behavior (Lesenciuc, 2017) which must willfully be conceived as favorable as possible for the personal and professional development of all employees in all institutions or organizations providing educational services.

What should be emphasized is that communication is two-way act and should be perceived according to the specific constituent parameters: sender, receiver, message, code, channel. The reference can be: which element of reality is spoken about, or the actual situation within which the message is sent. All of these are variable and if something related to one of the parameters does not work well, blockages may appear which impede communication.

Key aspects of a communication model based on valuing employees' emotional intelligence which can resolve many of the misunderstandings or conflicts that can appear in a school organization because of the one-way intra-institutional communication act.

Our proposal is to promote a communication model that values the stakeholder's communication skills and their emotional intelligence considering that Goleman (2018) sees it as a fundamental intuitive experience, which consists in being able to master an emotional impulse.

In a graphical representation like this (Figure 2) emotional intelligence means being able to place emotions at the center of the skills needed for life.

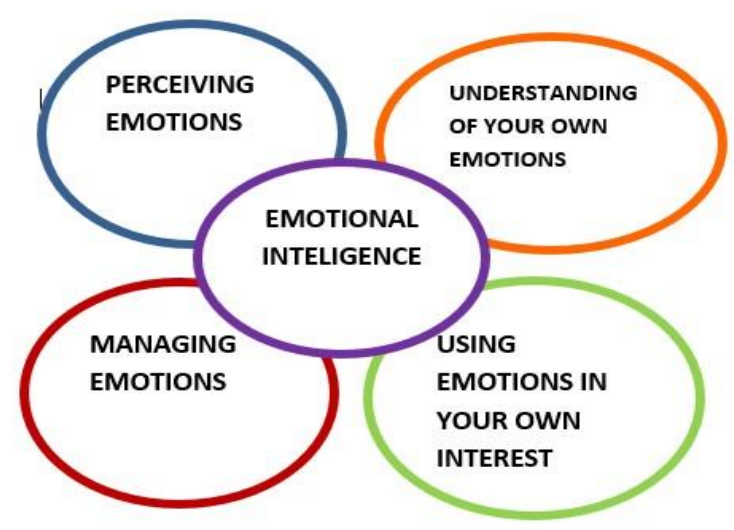

Figure 2. What Emotional Intelligence means?

Source: Authors

Daniel Goleman, the leader in the field, specialized in psychology and neuroscience, claims that successful managers and leaders are characterized by a high quotient of emotional intelligence (EQ).

Yeung (2012) begins the chapter What exactly is emotional intelligence? in a funny way: "If you haven't just landed on this planet, you may have heard of emotional intelligence. In fact, there are a lot of misunderstandings about its message. In a nutshell, emotional intelligence is the ability to identify, understand and manage both our states and feelings and the others".

According to the author, it can be divided into three sub-areas of expertise: 
I. Self-consciousness- which involves the ability to identify your own moods and feelings and understand how they affect others.

\section{Self-management- means:}

Step I: identify our own emotions and how they affect others;

Step II: setting goals and changing your emotions to personal advantage.

Most of the time, success often depends on our moods.

III. Interpersonal/inter-related intelligence is the third step to be taken to master your emotional intelligence and consists in identifying and controlling our emotions towards the others.

Rob Yeung, Goleman, Salovey and Mayer, as well as hundreds of other university teachers, business school teachers and managers agreed that emotional intelligence is extremely important for becoming successful in the workplace. Traditional intelligence - or a high IQ - has never been enough to become successful in life.

In the sub-chapter IQ and emotional intelligence, Goleman (2018) claims that IQ and emotional intelligence are not opposing competences, but rather separate.

It's therefore important to not mix the intellect with the emotional acuity and to value each person's emotional profile in the act of communication.

Carrying out a gender based comparative analysis, the author reveals the characteristics of men and women with a high IQ and also with a high EQ and we consider the information very important thus we think that our communication model should present this perspective in the school communication procedures in order to raise awareness among the employees about the need of knowing the different types of personality.

The man with a great IQ is characterized by the variety of intellectual interests and ambition, productivity, predictability, perseverance.

$\mathrm{He}$ is not worried about his own personality, he tends to be critical and condescending, hard to satisfy and repressed, inexpressive and detached, cold and indifferent.

The man with a developed emotional intelligence (with a high EQ) is: balanced from a social point of view, he is nice and cheerful.

He does not fall prey to worries, devotes himself entirely to people and causes, and is understanding and affectionate in his relationships. He has a great ability to take responsibility for his actions and adopts ethics.

The woman with a high IQ has intellectual trust and a wide range of intellectual and esthetic interests; she is fluent in expressing her thoughts, has a tendency to introspection, falls prey to anxiety and feelings of guilt, and hesitates to express her anger openly.

The woman with a developed emotional intelligence (with a high EQ) tends to be firm and express her feelings directly; she has a positive self-image; she is kind and communicative, expresses her feelings in an appropriate manner and does not have outbursts of anger which she would later regret; she establishes social relationships easily, is spontaneous and open to new experiences.

The author points out that in each of us there is a mixture of IQ and EQ at certain levels, but it is emotional intelligence that adds more qualities that really define us as human beings. (Goleman, 2018)

So far, research has shown that the benefits of valuing emotional intelligence include:

$>$ improving relations with people through effective and non-violent communication;

$>$ developing the ability to empathize;

$>$ increasing self-confidence which has the effect of encouraging autonomous thinking and creativity;

reducing stress level.

We believe that these are leadership strengths which can lead to better performance of employees and managers, whether they are top level managers, executive or middle level managers. 
Nicolescu and Verboncu (2007) state that, in essence, the main functions and attributes of the management are: prediction, organization, coordination, training and control.

The organizational function includes the set of actions that constitute the leading system, the managed system and the system of links between them. The coordination function comprises all the processes through which the manager's decisions are harmonized with the actions of the subordinates. The training function incorporates all the work processes that make the staff of the organization contribute to settling and achieving the expected goals, taking into account the factors that motivate it. The control function can be defined as the set of processes through which the performances of the organization and its components are measured and compared against the objectives and standards initially established, in order to eliminate the deficiences found and integrate the positive deviations from goals.

Throughout this process, in order to exercise these functions, we strongly affirm that the art of assertive and nonviolent communication must be valued, thus valuing the emotional intelligence of the employees and the managers as well.

So, that is the reason to promote such a communication model in every organization as an internal procedure, as an institutional document created at the level of each school, in order to take into consideration all the variables that make it unique.

The solution is to communicate assertively. The word assertive has a clear explanation in the Merriam-Webster Dictionary: assertive: disposed to or characterized by bold or confident statements and behavior.

From a psychological point of view, assertive communication is straighforward, open and honest, it allows the improvement of relationships with others through the ability to express your feelings, emotions and thoughts without damaging the integrity of others. (Boalcă, A. 2010)

We correlate this communicative behavior with the degree of valorization of emotional intelligence or with the quotient of emotional intelligence - EQ which implies: self-awareness, self-reliance, self-confidence, flexibility, empathy, motivation, optimism.

5 effective methods to be put into practice at the level of a school organization

In order to increase the employee performance in pre-university schools, such a communication model can be implemented in a descentralized manner by establishing an operational procedure, designed in the Commission for Quality Assurance and Evaluation at the level of each organization. This commission elaborates proposals for quality improvement taking into account the reference standards and the guide of good practices issued by ARACIP. One such proposal may be the one related to the implementation of a communication model based on the valorization of the emotional intelligence of the employees, teaching staff, auxiliary staff and management-management teaching staff.

We assume that all employees attend a briefing meeting, held by the manager of the institution announcing the need for change in the way they communicate in intra-institutional terms, in which, for example, one can suggest as a solution this communicative model of open mindset, with the valorization of the emotional intelligence of the employees and of the managers, a communicative model that respects each personality type, the temperament and the behavioral characteristics. We recommend that the manager use The Outward Mindset (2016) as a resource and present the experience of Captain Rob Newson, a U.S. Navy special forces career leader in the Special Operations community, who argues that, as long as SEAL candidates focus on the mission and those around them, they can overcome any difficulties, while if they get stuck self-looking inward and focus only on their personal needs, they fail to pass SEAL training. Newson's advice for those who want to successfully complete one of the most difficult training programs in the world is to focus on the mission and those around them. By analogy, the same applies in organizations. It is imperative to communicate in order to cooperate so that the activities of the institution are goal oriented. 
The methods which are believed to encourage bidirectional, nonviolent, assertive communication that led to the development of the well-being and self-esteem of the employees are intended to be applied to team building, meetings of various committees / interactive workshops in which principals should participate if we are talking about school institutions.

In the case of other types of organizations, these methods can be applied to: management meetings, department meetings, interdepartmental working groups, and if the organization is very large it can be done through representatives who have regular meetings with employees. Thus, we consider that five efficient active-participatory methods can be used as follows:

a. Role play - a method based on simulation activities of deficient interpersonal, intra-institutional communication in terms of enhancing the emotional intelligence of individuals, followed by the analysis of feelings and attitudes observed during the simulation;

b. Concept map - a useful scheme of ideas, a tool to organize concepts and statements in a graphic way to reveal or consolidate knowledge about emotional intelligence, about the difference between IQ and EQ etc.

c. The pyramid method - consists in working individually and as a group in order to solve a task, for example: Proposals in order to improve the communication between the manager and the employees. The steps of the method are: presenting the problem, working individually, in pairs and in larger groups, and then reporting solutions within the whole group.

d. Philips's method 6-6 - The first stage of the activity is to divide a large group (30 -50 people) into heterogeneous subgroups of 6 or 8 members, with a view to discussing a topic - without prior training - within a particular time limit. Each group appoints a secretary and a moderator of the discussions. Each group makes a short report. The reports are summarized: each secretary reads out the list of ideas of his group while all the other secretaries tick the ideas, they hear in order to exclude the same ideas from their lists. The organizer of the Phillips $6-6$ method collects all the lists and assemble them in a general report.

e. Panel discussion - The panel is a group of 5-7 people who have an informal discussion, without a prior plan, on a topic carefully prepared in advance, in front of silent audience. Those in the room are allowed to participate only by sending text messages to a message injector, the leader assuming this role. Messages are not signed and may contain: questions, corrections, additions, attitudes towards what the panel is discussing and towards the way in which the discussion is being conducted. From time to time, the message injector reads the notes out loud. The panel continues the discussion, taking into account the messages that have been read, answering, if desired, the questions, but without having to answer all of them.

\section{RESULTS OF APPROACHING SUCH A COMMUNICATION MODEL}

The implementation of the communication model presented above generates the following results:

$>$ changing the operational procedures regarding the intra-institutional communication process, from the perspective of valuing the emotional intelligence of the employees;

$>$ decentralization the process of decision-making in which the communication is carried out at the level of each department of the organization;

$>$ the existing Google Drive accessible electronic database at the institution level that contains summary information and schemes about: Intra-institutional communication; Emotional intelligence; The difference between IQ and EQ; Characteristics of individuals with a high EQ depending on gender; Examples of formulas to communicate assertively (non-violently);

$>$ Ways to reduce the tendency to trivialize the importance of emotions in communication;

$>$ Examples of good practice to remove certain barriers in communication and to avoid malfunctions or blockages in communication. 
The SWOT analysis of this communication model remains an opportunity to identify the strengths, weaknesses, threats and opportunities for its implementation within different types of organizations, especially in the context of the communication crisis generated by the COVID-19 pandemic.

\section{CONCLUSIONS}

The most important human process in establishing good interpersonal relation is communication. In our personal life and in our professional one, many misunderstandigs, many conflicts and bariers can be impeded if we take into consideration the role of emotions.

Every human being has a personality. In the Merriam-Webster dictionary, the personality is defined like the set of emotional qualities, ways of behaving etc., that makes a person different from other people.

A resourceful leader is that person who is able to understand this personal set of emotional qualities and ways of behaving of the employee. The holistic view that a manager should have about his employees is given by the triad: mind-body-soul and in order to determine them to perform better, the manager or the staff management should consider not only his or her's intelligence quotient, but also the emotional quotient and then act and communicate with the employee having that in mind.

Empowering employee's performance through an assertive communication and valuing his emotional intelligence as a manager means to: understand and manage his/her emotions; put them to good use, but also to firmly express your thoughts, ideas, feelings without damaging his/her's integrity. In order to do that, you need to be able to negociate, to discuss as long as it takes untill you can find solutions for the problem encountred.

The intra-institutional communication is seen nowadays like a one-way process, from the manager to employee, at least this were our observations towards some operational procedures regarding the intra-institutional communication in the public schools. The manager informs and the employee executes, applys, but if the internal communication procedure were based on concepts like: assertiveness, empathy, emotional intelligence, open mindset, then, maybe, the intra-institutional communication becomes a two-way process, more meaningful and thus oriented towards the organisation's objectives.

A communication model based on the integration of the concept emotional intelligence, structured in an operational procedure document, applied to the level of an organization department might be the solution to have more involved employees, more focused on objectives, more capable to empathize, more efficient and more productive, because increasing their selfesteem and valuing their ideas, their feelings create the contexts of well-being, of being appreciate.

Therefore, we want to emphasize the need that in the human resource management, as a manager you need to be a good communicator, to have transversal competences in order to cascade to your employee communication models based on linguistics/semantics, psychological and management knowledges.

\section{ACKNOWLEDGMENTS}

This paper is a result of the research performed within the Doctoral School of Management from the Bucharest University of Economic Studies. 


\section{REFERENCES}

Assertive (n.d.). In Merriam-Webster's online dictionary. Retrieved from https://www.merriamwebster.com/dictionary/assertive.

Boalcă, A. (2010). Comunicarea asertiva - cheia intelegerii (Assertive communication - the key of understanding). Psychologies, https://www.psychologies.ro/dezvoltare-personala-cunoastete-2/comunicarea-asertiva-cheia-intelegerii-1320416?v=f5b15f58caba

Goleman, D. (2018). Inteligența emoțională, București, Curtea Veche Publishing.

Jakobson, R. (1960). Closing Statements: Linguistics and Poetics, in Sebeok T. A., Style in language, Cambridge Massachusetts, MIT Press.

Lange, A., \& Jakubowski, P. (1976) The Assertive Option. Illinois: Research Press Co.

Lesenciuc, A. (2017). Communication Theories, fromhttps://www.afahc.ro/ro/facultate/cursuri/2017_teorii_ale_comunicarii.pdf.

Nicolescu, O., \& Verboncu, I. (2007). Managementul organizaţiei, Editura Economică.

Pânișoară, I. O. (2003). Comunicarea eficientă, Metode de interacțiune educațională, Iasi, Editura Polirom.

The Outward Mindset (2016). Arbinger Properties, L.L.C.

Tuțu, I. (2017). Procedure regarding the internal and external communication, from http://ceac.pedagogicbacau.ro/wp-content/uploads/2017/10/PO_7_COMUNICARE.pdf.

UPB's Polytechnic Primary School internal communication procedure, Accesed 29.10.2021 at http://www.imst.pub.ro/Upload/Facultate/asigurarea_calitatii/PO21SPP10_comunicare_intern a.pdf

Watzlawick, P., Beavin-Bavelas, J., \& Jackson, D. (1967). Some Tentative Axioms of Communication. In Pragmatics of Human Communication - A Study of Interactional Patterns, Pathologies and Paradoxes., New York, W. W. Norton.

Yeung, R. (2012). Dezvoltarea inteligenței emoționale, București, Meteor Press. 